\title{
CONFLICTED HERITAGE: VAlUes, Visions and PRACtices in the Management AND PRESERVATION OF CULTURAL AND ENVIRONMENTAL HERITAGE
}

\author{
G.W. KEARSLEY AND M.C. MIDDLETON
}

Public History Review, vol 13, 2006, PP23-34

T he appreciation of cultural and natural heritage has a very long history ${ }^{1}$ but it has risen to major significance in recent decades, both in daily lives and in an increasingly important cultural tourism. ${ }^{2}$ Traditional styles and perspectives in heritage identification, preservation and management have given way to more recent trends. Today, an increasing scale and even newer perspectives mean that the future focus of heritage studies is more likely to be on the consumers of heritage than simply on the product itself.

The fragility, scarcity and vulnerability of heritage, in all its forms, mean that preservation and conservation will also be critical, managed as much through visitor management as through material conservation. The diversity of consumer demand, the increasing diversity and plurality of heritage identification, the proliferation of stories that are to be told (or are wished to be told) and the intrinsically perceptual nature of heritage, both cultural and natural, all mean that conflict, both overt and latent, is a fundamental component of heritage and its consumption.

\section{THE NATURE OF HERITAGE}

Heritage has been defined in many ways but Hall's ${ }^{3}$ simple definition works well, at least in tourism; heritage, he says, is what we want to keep and hand on to future generations. This can thus apply equally effectively to artefacts, customs, buildings and landscapes. Thus, some heritage has been consciously recognised by past generations; we, ourselves, continue both to define and to create heritage.

If heritage is what we want to keep, this raises an important question as to whom 'we' might be. There are, in fact, of course, many forms of 'we', defined by gender, demography, culture and many other things. Individual and group perceptions, values and choices define heritage and because there are many groups defined as 'we' and 'our', and many 'others', and because power 
relationships and value systems at all levels may be incongruent or even mutually exclusive, conflict and choice are inevitable.

We ourselves are the beneficiaries of choices and decisions made in the past. Some of these are consciously framed within the concepts of heritage and stewardship that we recognise ourselves; others are more accidental or incidental. Thus, we can see the relics of earlier civilisations consciously preserved, in the form of the great icons of material heritage, at Stonehenge, the Pyramids or in the Great Wall. Of course, such monuments have not always been protected for all of their life, often their survival has lain in their sheer size and durability. Many a castle and abbey was quarried for its ready made building stones, many a statue defaced with Puritan zeal. In southern New Zealand, memorial oaks were planted for those who never returned from the Great War; ${ }^{4}$ only recently have the accompanying markers been restored and some missing trees replaced.

As the nineteenth century advanced, it became common to see traditional agricultural landscapes preserved through the actions of private organizations such as the Council for the Preservation of Rural England and later the National Trust. Later, governments became involved through planning regulations and through agencies such as English Heritage or the QEII Trust in New Zealand. Similarly, it was not until advancing technology and human dominance of the landscape made natural environments vulnerable was wilderness venerated in poetry and painting, ${ }^{5}$ leading eventually to the National Park movement, in which New Zealand was an early pioneer. ${ }^{6}$ The choice of where Parks should be located (in the 'waste' land unsuitable for agriculture and forestry) determined much of what came to be seen as natural heritage. Thus, in New Zealand, the early Parks were established to protect bush and mountains; to this day, native grasslands and wetlands remain under-represented. In England, the Parks were not established until nearly a century later than in New Zealand, the absence of real wilderness meant that they preserved very different, human modified landscapes.

We are also the inheritors of buildings and landscapes that have survived by chance and that might or might not have had significance for past generations. In England, the robust ridges and furrows of Saxon cultivation remain throughout much of the North and Midlands, despite the imposition of enclosure and dramatic landscape change. Similarly, the earthworks and street patterns of lost villages are readily visible from the air or in the rays of low angle sunlight. In New Zealand, the Central Otago goldfields sites have been assembled into a heritage park and protected, despite them being no more than industrial scarring when created. Indeed, it is incongruous to note that the Department of Conservation and the Regional Council that afford them protection would never allow a modern operation to leave unrestored sites on such a scale.

Much vernacular architecture and many historic street patterns remain as heritage precincts not so much through preservation as by chance. While London's architects planned great avenues and piazzas after the Great Fire, the 
citizens of the City simply replaced their burned buildings in stone upon their old sites and the Mediaeval street pattern was preserved. ${ }^{7}$ Dunedin and Oamaru have been the beneficiaries of the absence of development pressures and exciting heritage architecture has remained to be recognised through the absence of competing land uses and structures and the lack of a commercial imperative, later to be discovered in tourism.

The geographer H.C. Darby saw the modern landscape as a palimpsest, a much used parchment on which the 'writing' of past eras could be faintly discerned or else had been retained. Celtic fields, Roman roads and ancient hedgerows were the inerasable writing of the past over which was scrawled industrial and modern development, but which still can be seen and recognised as heritage landscape. Yi-fu Tuan ${ }^{8}$ saw the landscape as 'a repository of human striving' It is also a repository of human conflict, both in representation and in choice.

\section{The Values of Heritage}

Heritage is said to confer many values, including scientific value and artistic merit. For those who share a common heritage there is a sense of belonging and a structured self-identity; heritage provides the security of known roots and a shared past. Heritage can be an important component of national identity as well. ${ }^{9}$ Through tourism, heritage provides visitor revenue. Some of this is derived from admissions, ticket sales and the like, but the vastly greater return comes from accommodation, food and drink, transportation and retail sales. Heritage sites, sights and ways of life are increasingly the icons around which marketing campaigns and urban, regional and national 'brands' are structured. ${ }^{10}$ Much economic development, whether it be urban or rural, has been based upon heritage tourism; the tourist industry has proved to be one of the few effective counters to the adverse economic re-structuring consequent upon globalisation. Dunedin itself provides a clear example of how heritage tourism can be used as the catalyst for economic reform. ${ }^{11}$

Swarbrooke ${ }^{12}$ identified a number of reasons for the recent growth of heritage tourism; by implication, these highlight the essential economic and nonmarket values of tourism. In market terms, there are higher levels of education and experience, longer active retirements and increased retirement income, together with a massive increase in the frequency of 'gap' years and the rise of short break holidays. Motivations for heritage tourism are said to include the search for roots, stability and identity, the desire to learn, a search for authenticity in an increasingly commodified world and the perceived high status of cultural experiences. On the supply side, recent years have seen a massive increase in product and promotion, attendant upon a Government focus on cultural and heritage identity. In many of the settler societies of the new world, there has been a post-colonial renaissance of indigenous culture, linked closely with heritage tourism; Maori, Australian Aboriginals and the First Nations are all examples of 
this. In Europe, the re-emergence of national identity has been accompanied by a focus on culture and heritage.

\section{CONFLICT AND COSTS}

Apart from the undoubted benefits, both economic and more intangible, that heritage has generated, often realised through tourism, there are also costs to be borne. Heritage maintenance and management incur costs directly and indirectly and in many ways. Direct costs involve the conservation and maintenance of sites, interpretation and visitor management, through staffing and through the acquisition of new sites as perceptions of heritage change and new trends in visitor product are realised. Similarly, indirect costs are incurred through opportunity cost as alternative uses are foregone, or through the increased cost to visitors and other users of heritage, as new uses and perspectives are found. Inevitably, then, when choices have to be made, conflict is always inherent.

Examples include the conflict between competing visitor demands, as when a tract of National Park has the potential to be strictly reserved as wilderness for an elite minority to enjoy, or to be protected from high use damage through the installation of boardwalks, high quality tracks and the like, measures which provide a 'wilderness' experience for a large market, but destroy it for others. In the same way, tracks may be open to mountain bikers and waterways open to jet skis or jet boats with all of the conflict that that implies. Increasingly, both natural and built heritage are threatened by development options, as when wild rivers are seen as options for irrigation and hydro-power ${ }^{13}$ or historic buildings cleared under commercial imperatives. The pressures of agricultural change and tourist development have huge consequences for heritage landscapes of natural environments or traditional farming. Thus, in New Zealand, both popular resort areas, such as the Wakatipu basin, and traditional country towns are threatened by development pressures; traditional hedgerows and stone walls and field patterns in Europe have given way to large scale agri-business practices. Often, conflict among user groups in more traditional settings is exacerbated by the increasing costs and expanding focus of product trends, some of which were identified by Swarbrooke ${ }^{14}$ as including open air museums on a substantial scale and themed heritage centres, with significant entry fees.

\section{CONFLICT, INTERPRETATION AND AUTHENTICITY}

Heritage values are grounded in the interpretation that is offered, whether on-site or in the broader historic perspectives of a society or group. As has been noted, cultural heritage is effectively a story, but the question of whose story it might be remains of paramount importance. For every story there are many, sometimes conflicting, tellers. Some stories, such as those of inarticulate or exploited classes and those of indigenous or colonised peoples have only recently come to be heard, certainly in their own words. Some stories now will always be silent. So, just as the victors are said to write history, so too do they define and depict heritage as well. Accordingly, different markets will see heritage products in very 
different lights, especially those relating to war and social conflict, as so many heritage sites do. Time may well heal many wounds, but it was nonetheless deemed expedient to label the opposing forces in the 2005 bicentennial of Trafalgar as the 'red' and 'blue' flotillas. Clearly, then, sites such as the World War I trenches, the Normandy D Day beaches, the Burma railroad and the atomic memorials at Hiroshima will have very different imagery and associations for different groups. In the same way, memorials that represent colonial history, such as the tree at One Tree Hill, Auckland or Victoria's statue in Queen's Gardens, Dunedin, may be seen as current symbols of oppression by some, fit only to be defaced or destroyed. Sometimes, it is questioned whether or not different cultural values, and especially minority cultural values, really exist, or whether they are assumed or exaggerated for political advantage and economic gain, an issue that is addressed below in the context of New Zealand.

Not only are there conflicts of symbolism and meaning, but also there is an ongoing tension between presentations of heritage and expectations of authenticity. Thus, an original Turner in the Dunedin Art Gallery or an original Hotere in the Carey's Bay Hotel, Port Chalmers, are equally authentic, although the former may be geographically, if not culturally, far from its original provenance. Indeed, the authenticity of heritage items, whether they be the Elgin Marbles or tattooed heads, remote from their cultural context, raises many ethical and aesthetic questions.

Much heritage is modified while retaining some authenticity. Many of the historic re-creations in New Zealand, such as the well-known Shanty Town and Old Cromwell and the more humble historic museums such as the Taieri Historical village near Dunedin, balance authentic structures with their placement in an entirely different location and context, as old buildings are relocated and reconstructed for a variety of reasons. Some heritage items are entirely inauthentic. Some, such as the Haggis Ceremony in Dunedin, are unashamedly invented and do not purport to be anything other than a tourist entertainment; others, such as some souvenirs, are presented with an implication of authenticity when in fact serious issues of intellectual and cultural property exist. The use of Maori motifs in cheap souvenirs - Taiwanese made tikis or Chinese made 'Maori' patterned tea-towels - are but one local example of a global problem. The whole field of commodification and trivialisation versus authenticity in situ is replete with conceptual conflict of a fundamental nature.

The portrayal and expectations of wildlife present a similar range of challenges. Old style zoos are giving way to much more authentic habitats, but even in eco-tourism, where authenticity is the sine qua non, swimming with dolphins or the parades of penguins past veritable stadia, complete with floodlights, both in New Zealand and Australia, raise similar questions of the conflict between staged heritage and authenticity. Certainly, when penguins, as at the Curio Bay petrified forest, come ashore at natural sites, potential conflict between visitors and wildlife is an ongoing issue. Some visitors keep their distance, but many encroach upon the birds, seeking the perfect penguin picture. 


\section{Conflict, Preservation and the IDentity of Heritage}

Even the need for conservation and restoration raises issues of conflict. If landscapes are evolving palimpsests, it could be asked at what point the process of evolution should be frozen, through permanent conservation. How far should the fossilisation of landscape change be effected through processes of restoration? An example of these conflicts lies in the various goldfields sites of southern New Zealand. On the West Coast the rapid regeneration of rain forest has meant that many Nineteenth Century sites have become all but lost through natural processes. In the drier climate of Central Otago, many sites are preserved in the Otago Goldfields Park. Even here, however, wilding pines and sweet briar are over-running former sluicing sites and energetic efforts are required to retain the original barren landscapes of goldfields sluicing, the incongruity of preserving such sites has been mentioned above.

Further conflicts arise over the meaning and purpose of heritage. Few would argue that Stonehenge or Waitangi are heritage sites, but, increasingly, popular entertainment and the trivial have been awarded heritage status. Thus, Gracelands, Penny Lane and Coronation Street have joined Dicken's house and Anne Hathaway's cottage; perhaps Never-Never Land may one day join them. Locally, heritage status of sorts has been bestowed upon the remarkably kitsch paua house at Bluff. Then, too, there is the growing conflict between accurate portrayal and popular nostalgia with a continuing tension between scholarly interpretation and a more popularly palatable sense of comfort and entertainment. ${ }^{15}$ So, for example, interpretations of past industrial eras are far more likely to show the pub, shops, fairground and school than the workhouse fever hospital or debtors' prison. Similarly, our images of the Mediaeval are likely to revolve more around knights, jesters and banquets than around poverty, leprosy and the Black Death. There is nothing wrong with such portrayals, but the difference between past reality and romantic imagery, heritage and entertainment, is often hard to maintain.

\section{TouRISm AND HeRITAge IN SOUtHeRn New ZeaLAND}

In southern New Zealand, as in so many other places, the conflicts imposed by commercial imperatives, and by tourism in particular, are paramount in ongoing heritage management. ${ }^{16}$ Tourism, in particular, both defends and destroys heritage. As has been noted above, tourist values and revenue protect heritage through nature conservation and eco-tourism as in the protection of albatross and yellow-eyed penguin. Tourism provides an alternative to undesirable extractive practices as with the cessation of native forest logging on the West Coast. Heritage landscapes, both old and new, are protected by their status and value as tourism resources. In the same way, tourism drives the rehabilitation and protection of heritage buildings and townscapes in Dunedin, Oamaru and many smaller places such as Lawrence and Ranfurly. ${ }^{17}$ 
In the same way, though, tourism and its consequences both compromise and destroy. Essential as well as unnecessary infrastructure damage landscapes and experiences. Ski-field access roads scar mountain-sides; board walks and bridges reduce wilderness experiences for some. The very popularity of tourism and the numbers it generates lead to changed experiences, crowding and displacement. Inappropriate resort development and expansion are instrumental in creating dramatic landscape change. This is happening in major resorts, such as Queenstown and Wanaka, and in smaller places, such as Luggate and Hawea, where large sub-divisions are driven by displacement from the larger centres. Two examples of how differing perceptions and cultural values are now presented; these demonstrate how apparent conflict arises and how the recognition of difference can lead to better management and, ultimately, heritage conservation and enhancement.

\section{Perceptions of Crowding AND OF WiLderness}

The concept of wilderness and natural heritage is itself a cultural construct. ${ }^{18}$ It used to be thought that the main impacts of tourism would be damage to the physical and ecological environments, and, certainly, that is not inconsiderable, but today it is realised that social impacts and crowding, in particular, are the main sources of dissatisfaction and conflict. Crowding is the negative perception of the numbers of groups or individuals in a particular setting and, as a perceptual construct, degrees of crowding relate the expectations and perceptions of the individual; crowding is not a measure of density, although, of course, it reflects this. Perceived crowding may lead to various avoidance behaviours, displacement and other mitigating strategies, and is often used as an indicator of social carrying capacities having been breached. Crowding may potentially be found in all tourism sites and to an extent it is a New Zealand wide phenomenon, but at present it is largely confined to a series of popular sites and facilities, notably tramping huts. It is also largely a seasonal phenomenon, but not entirely so. ${ }^{19}$

Higham ${ }^{20}$ measured crowding throughout South Island tramping tracks and Kearsley ${ }^{21}$ undertook a national survey of the backcountry and subsequently measured crowding and displacement in front country settings, where similar patterns are emerging. ${ }^{22}$ Approximately half of the overall samples felt that they had experienced more people than expected on their trip, and this was true for all sub-groups. In the backcountry in general, while thirty per cent overall felt quite uncrowded, some sixteen per cent reported moderate to extreme crowding. This perception is held by both domestic and overseas visitors, with the latter dominating the most popular tracks. In general terms, about a fifth of all respondents expected to see less people than they actually did and thirty-four percent would certainly have preferred to see fewer.

Crowding has serious implications for satisfaction. Twenty-two per cent of Kearsley et al's ${ }^{23}$ sample said that crowding had affected their enjoyment, and some two thirds of those said that it had done so moderately to extremely. Many 
of those interviewed sought wilderness and wilderness experiences, which they tend to associate with the National Parks environment. Sixty-nine per cent of the sample expected to encounter wilderness conditions, and most of those did in fact find them. Of the minority who did not, most said it was because tracks were too well formed, signed and hardened and a quarter, mainly on the Great Walks, believed that overnight huts were too comfortable and even luxurious. Over a third of each group cited crowding as detracting from wilderness values. Boat and aircraft noise were also mentioned by significant numbers. ${ }^{24}$

Many attempts have been made overseas to explore the dimensions of the wilderness image.$^{25}$ The notion that wilderness could be perceived and encountered differentially by various people in environments that were more or less developed has been taken further. In various studies, wilderness users, the general public or international visitor users of the Conservation Estate were asked to state the extent to which they accepted various facilities (huts, tracks and bridges), characteristics (remoteness and solitude) or developments (exotic forests and mining) in wilderness areas. Kliskey and Kearsley ${ }^{26}$ show how responses to such a question may be used to group people into discrete purism classes and to plot the extent to which specific environments provide wilderness for various groups. In these studies, it appears that the highly purist required a pristine ecological wilderness, but that the majority could find wilderness values in places that had been part developed.

Visitors have varying perceptions of wilderness and one single definition does not accurately portray the extent of wilderness as everyone regards it. An approach to understanding the spatial extent of such varying wildernesses can be made through GIS based wilderness image mapping. Wilderness perception maps are produced by 'buffering' or excluding those areas of a specific environment that do not accord with a particular group's view of wilderness. ${ }^{27}$ Thus, areas of mining would be excluded from non-purist wilderness areas and vehicular access and hydro sites would be further excluded to identify neutralists' wilderness, so that the more purist the perception, the less extensive the wilderness. Such mapping has been carried out for a substantial part of the Southwest of the South Island, especially Northwest Nelson, the Fiordland and Mount Aspiring regions and adjacent areas. This suggests that the saturation of pristine wilderness might be averted, as many found satisfaction in areas unacceptable to the purist minority. In these places, natural heritage could be sustained as an acceptable form of wilderness for the majority by providing hardened tracks, boardwalks, huts and other facilities.

This approach is a significant advance upon the notion that there is one wilderness for all people and that wilderness requirements can be accommodated only in the pristine wildernesses that legislation defines. In the period of its existence, the Department of Conservation has allowed many structures to be run down and has removed many more, partly to facilitate the promotion of wilderness. While it is necessary to restrict the extent of infrastructure to that which can be adequately maintained, it is false logic to 
assume that this adds to the wilderness resource, since, for many people, wilderness is compatible with the presence of such structures. For many, they are necessary for wilderness to be enjoyed.

\section{Conflicting Cultural Values}

The images that visitors have of environments can be extended beyond the study of wilderness. As noted above, there is often a perception that differing cultural values may be used for political positioning or economic gain. This is certainly the case in New Zealand, where some suspect that such might be the motivations for the assertion of a different attitude towards the natural world. Kearsley, Coughlan and Ritchie ${ }^{28}$ examined the ways in which international visitors and domestic holidaymakers perceive both natural and developed environments, using MultiDimensional Scaling (MDS). An increasing number of tourism researchers have used MDS procedures in examining destination image and positioning, although it was first used to indicate the differences and similarities between recreational activities. ${ }^{29}$ Fodness ${ }^{30}$ examined consumer perceptions of Florida tourist attractions, while Cossens ${ }^{31}$ and Driscoll ${ }^{32}$ examined the position held by New Zealanders of New Zealand, relative to other international tourist destinations.

In the study described here, a wide range of popular and less well-known natural and developed areas were used to examine both domestic and international perceptions. Forty sites were analysed, ranging from walking tracks, such as the Routeburn, to commercial sites such as Whakarewarewa. The aim of the MDS procedure was to identify the dimensions along which people differentiated destinations and then to show how individual places relate to those dimensions. It was interesting to note that were no great differences in perception between New Zealand residents and overseas visitors, neither for natural environments nor for resorts and other built environments. In fact, quite separate groups of people differentiated among places using very similar criteria. In other words, different markets appeared, on the surface, not to use different criteria in making judgements about destinations; most people seemed to see most places in much the same sort of way.

Specifically Maori perceptions of the environment were later examined), also through the technique of multi-dimensional scaling and using the same data set, but isolating out Maori from the wider domestic New Zealand population. When Maori and Pakeha (non-Maori New Zealanders) evaluate the developed world of resorts and facilities they do so in similar ways; there is clearly no separate Maori world view in this context, so that for developed places, at least, there is a common set of images that is not affected by ethnicity. This is not the case for the natural world. Maori construct their principal images around recreation, holidays and food gathering whereas non-Maori perceive the natural world primarily in terms of wilderness, challenge and accessibility and set this against commercialisation, seasonality and family orientation. Secondary Maori perceptions relate to heritage and a Maori focus, seasonality and degrees of commercialisation. The secondary perceptions of non-Maori emphasise many of 
the things that Maori select in their first dimension, namely the suitability of an environment for families and holidays. Nowhere do Maori focus on wilderness, challenge, peace or solitude. In their intellectual environment, the coastline, the periphery of wilderness and the front country are significant for use and recreation, but the deep backcountry seems separate, a notion consistent with the concept of waahi tapu (sacred places). The mountains are venerated as tupuni (ancestors) and as taonga (treasures), to be respected but not necessarily physically used. In accordance with this, most wilderness surveys in New Zealand show a relative absence of Maori in the back country. ${ }^{33}$

Conservation planning in New Zealand is currently based on the need for modelling, monitoring and managing physical impacts upon the environment, while a more recent, growing body of work relates to social impact assessment, through crowding, displacement and the like. Maori have a formal consultative status in the preparation ofplans and strategies, as well as a significant role in Conservation Boards but, in conservation planning, it is apparent that a deeper appreciation of cultural values is required as well. The work outlined above has demonstrated that a different Maori wilderness ethic exists and that it can be revealed by accurate scientific analysis as well as by the more traditional qualitative approaches.

\section{CONCLUSION}

The focus of heritage research and management is still focused on the product and its presentation; the focus on visitors is still largely traditional, involving demographics, expectations and market segmentations of a traditional and somewhat routine kind. Heritage, though, is fundamentally a personal experience, about the meaning of place and of self in place, so that emotions and beliefs are as important as aggregate statistics, essential though those are.

The huge variety of cultures, as providers and consumers of heritage, and the infinite variability of personal perceptions mean that competition, conflict, incompatibility and tension underlie, and will increasingly underlie, the presentation of heritage, especially as a tourism product of increasing significance. Inevitably, then, it is here that much future research must be focused, both for the sake of heritage itself and the industries and communities that rely on it.

\section{ENDNOTES}

${ }^{1}$ M. Feifer, Going Places: the ways of the tourist from Imperial Rome to the present day, Macmillan, 1985.

${ }^{2}$ C.M. Hall and G.W. Kearsley, Tourism in New Zealand: An Introduction, Oxford University Press, Auckland, 2001.

${ }^{3}$ C.M. Hall and S. McArthur, Heritage Management in New Zealand and Australia: Visitor Management, Interpretation, and Marketing, Oxford University Press, Auckland, 1993.

${ }^{4}$ E. Pawson, 'The memorial oaks of North Otago: a commemorative landscape', in G.W. Kearsley and B.B.

Fitzharris, Glimpses of a Gaian World; Essays on Geography and Senses of Place, in honour of Professor Peter Holland, School of Social Science, University of Otago, Dunedin, 2004, pp115-132.

${ }^{5}$ C.J. Glacken, Traces on the Rhodian Shore, University of California Press, Berkeley and Los Angeles,

1967; R. Williams, The Country and the City, Oxford University Press, London, 1973.

${ }^{6}$ Hall and Kearsley, op cit. 
${ }^{7}$ H. Carter, An Introduction to Urban Historical Geography, Edward Arnold, London, 1983.

${ }^{8}$ Y-F Tuan, Topophilia, Prentice Hall, Englewood Cliffs, N.J., 1974.

${ }^{9}$ Hall and McArthur, op cit.

${ }^{10}$ G.W. Kearsley, S. Russell and R. Mitchell, 'The contribution of front country tourist recreation towards increased crowding and dissatisfaction in New Zealand's natural environments', in M.R. Robinson, P. Long, N. Evans, S. Sharpley and J. Swarbrooke, Reflections on International Tourism: Motivations, Behaviour and Tourist Types, Business Education Publishers Ltd, Sunderland, 2000, pp243-252.

${ }^{11}$ G.W. Kearsley, 'Public acceptance of heritage tourism as an instrument of urban restructuring: the case of Dunedin', in C.M. Hall, J.J. Jenkins and G.W. Kearsley (eds), Tourism planning and policy in Australia and New Zealand: Issues, cases and practice, Irwin, Sydney, 1997.

$12 \mathrm{~J}$. Swarbrooke, 'Towards a sustainable future for cultural tourism: a European perspective', in M. Robinson, N. Evans and P. Callaghan (eds), Tourism and Cultural Change, University of Northumbria Press, Newcastle,1996, pp227-256.

${ }^{13}$ G.W. Kearsley, 'Tourism and resource development conflicts on the Kawarau and Shotover Rivers', GeoJournal, vol 29, no 3, 1992, pp263-270; P.A. Memon and G.W. Kearsley, 'Resource based urban development in the peripheral regions of New Zealand', in G.W. Kearsley and Fitzharris, B.B. Southern Landscapes: essays in honour of Bill Brockie and Ray Hargreaves, Dunedin, 1990, pp329-346; B.B. Fitzharris, B.B. and G.W. Kearsley, 'Recreational planning and hydro development in the Waitaki Valley: some lessons for the Clutha', Proceedings, IXth New Zealand Geographical Society Conference, University of Otago, Dunedin, 1978, pp80-84.

${ }^{14}$ Swarbrooke, op cit. ${ }^{15}$ ibid.

${ }^{16}$ G.W. Kearsley, 'Heritage Management : A Regional Approach', in C.M. Hall and S. McArthur (eds), Heritage Management in New Zealand and Australia: Visitor Management, Interpretation and Marketing, Oxford University Press, Auckland, 1993, pp197-208.

${ }_{17}^{17}$ G.W. Kearsley, 'Rural Tourism in Otago and Southland, New Zealand', in R. Butler and C.M. Hall, Tourism and Recreation in Rural Areas, John Wiley and Sons, Chichester, 1998, pp81-96.

${ }^{18}$ Glacken, op cit.

19 J.E.S. Higham and G.W. Kearsley, 'Wilderness perception and its implications for the management of the impacts of international tourism on natural areas in New Zealand', in Tourism Down-under: A Tourism Research Conference, 6-9 December, 1994, Department of Management Systems, Massey University, Palmerston North, 1994, pp505-529.

${ }^{20}$ J.E.S. Higham, 'Wilderness Perceptions of International Visitors to New Zealand: The perceptual approach to the management of international tourists visiting wilderness areas within New Zealand's Conservation Estate, Unpublished PhD thesis, University of Otago, Dunedin, 1996.

${ }_{21}$ G.W. Kearsley, D.P. Coughlan, J.E.S. Higham, E.C Higham and M.A. Thyne, Impacts of Tourist Use on the New Zealand Backcountry, Research paper no1, Centre for Tourism, University of Otago, Dunedin, 1998.

${ }^{22}$ Kearsley, Russell and Mitchell, op cit.

${ }^{23}$ ibid.

${ }^{24}$ G.W. Kearsley, 'Tourist numbers and wilderness perception in the South Island of New Zealand', in Kearsley and Fitzharris, Glimpses of a Gaian World, pp43-254.

${ }^{25}$ R.C. Lucas, 'Wilderness perception and use: the example of the Boundary Waters Canoe Area', Natural Resources Journal, vol 3, 1964, pp394-411; J.C. Hendee, W.R. Catton, L.D. Marlow and C.F. Brackman, 'Wilderness users in the Pacific Northwest: their characteristics, values and management preferences', USDA Forest Service Research Paper PNW-61, Portland, Oregon 1968; G.H. Stankey, The perception of wilderness recreation carrying capacity: a geographic study in natural resource management, PhD thesis, Michigan State University, East Lansing, Michigan, 1971; T.A. Heberlein, 'Social psychological assumptions of user attitude surveys: the case of the Wildernism Scale', Journal of Leisure Research, vol 5, no 3, 1973, pp18-33; J.T. Beaulieu, Defining the components of the environmental image for use as a predictor of decision to participate, PhD thesis, Utah State University, Logan, Utah, 1984.

${ }^{26}$ A.D. Kliskey and G.W. Kearsley, 'Mapping Multiple Perceptions of Wilderness in North West Nelson, New Zealand: A Geographic Information Systems Approach', Applied Geography, vol 13, 1993, pp203223.

${ }^{27}$ A.D. Kliskey, 'Wilderness Perception Mapping: a Geographic Information Systems approach to the application of wilderness perceptions to protected areas management in New Zealand', PhD thesis, University of Otago, Dunedin, 1992.

${ }^{28}$ G.W. Kearsley, D.P Coughlan and B.W. Ritchie, 'Images of New Zealand holiday destinations: an international and domestic perspective', Research Paper Number 2, Centre for Tourism, University of Otago, Dunedin, 1998; G.W. Kearsley, D.P. Coughlan and B.W. Ritchie, 'Images of New Zealand natural areas: an international and domestic perspective', Research Paper Number 3, Centre for Tourism, University of Otago, Dunedin, 1998.

${ }_{29}$ J.R.B. Ritchie, 'On the derivation of leisure activity types: a perceptual mapping approach', Journal of Leisure Research, vol 7, 1975, pp128-140.

${ }^{30}$ D. Fodness, 'Consumer Perceptions of Tourist Attractions', Journal of Travel Research, Spring, 1990, pp3-9.

31 J. Cossens, Positioning a Tourist Destination: Queenstown: A Branded Destination?, Masters thesis, University of Otago, Dunedin, 1989. 
Public History Review, vol 13, 2006

\begin{abstract}
${ }^{32}$ A. Driscoll, Destination New Zealand's Position: A Multidimensional Scaling Approach, Masters thesis, University of Otago, Dunedin, 1990.

${ }^{33}$ Kearsley, Coughlan, Higham, Higham and Thyne, op cit; Higham, op cit.
\end{abstract}

